\title{
Performance Comparison of Wind Energy Conversion System Technologies
}

\author{
A. P. Ferreira**** and C. B. Vaz $* * * *$ \\ $\{$ apf, clvaz\}@ipb.pt \\ *Polytechnic Institute of Bragança, Campus de Santa Apolónia, Apartado 1134, 5301-857 Bragança \\ **CISE - Electromechatronic Systems Research Centre, University of Beira Interior, Covilhã (Portugal) \\ *** CGEI, Centre for Management and Industrial Engineering, INESC TEC (Portugal)
}

\begin{abstract}
This paper intends to give some insights on the performance comparison of two main conversion system technologies from a set of wind farms from two major promoters in the Portuguese wind energy sector. Conversion system technologies under analysis are based on the generator type, synchronous and asynchronous, which are the basis of the dominant technological trends in actual market. The performance assessment is accomplished using Data Envelopment Analysis (DEA) methodology, by computing the Malmquist index for group's comparison. From the obtained results, it is possible to conclude that farms with conversion systems based on synchronous generators have a better performance than the ones using conversion systems based on asynchronous generators. These conclusions may support the decision makers in repowering and overpowering processes.
\end{abstract}

Index Terms - DEA, Malmquist index, Wind energy, Wind farms, Wind turbine generators.

\section{INTRODUCTION}

In order to cope with the worldwide climate change and the expected increase of the electricity demand, lowcarbon and energy efficient technologies are required, mainly based on renewable energy sources. In this scenario, wind power's scalability and its speed of deployment makes it an ideal technology, capable of decarbonizing the power sector, by reducing the usage of fossil fuels.

Wind energy technology has reached a good energy balance. The greenhouse gas emissions related to the manufacturing, installation, servicing and decommissioning of a wind turbine are generally restored after the first months of operation. For the rest of its 20 years of lifetime, wind farms contribute to bring back the emissions for the pre-industrial levels.

According to Global Wind Energy Council (GWEC), installed wind power capacity has grown to cumulative worldwide installation level of $369,5 \mathrm{GW}$, with 51,5 GW alone installed in 2014. In the last year, Europe total installed capacity has been surpassed by Asian markets (India, China). Portugal accounts for about five percent of the wind energy installed capacity of the European Union, with approximately 4,9 GW of accumulated installed capacity in 2014 which is capable to generate about $15 \%$ of the electrical energy consumption [1].
Despite the advantages inherent to a renewable energy source, wind energy has also some drawbacks. The small power density of the wind leads to wide and material extensive turbines, thereby hindering the on-site assembly and the electrical infrastructure. Concerning the prime source, wind is stochastic in nature and essentially ruled by random meteorological changes. Due to its intermittent and unpredictable behavior, wind energy systems do not have the ability to produce electrical energy following load requirements which implies structural changes in power systems as, for instance, the usage of storage systems and/or coupling hydro and wind systems to smooth the output pattern [2]. The inherent variability of wind power is also raising concerns regarding the reliability and cost-effectiveness of the transmission and distribution power systems in supporting large wind farms [3].

The life span of the first wind farms is coming to an end, which implies repowering processes aiming at augmented efficiency and reliability of the wind turbines. From the available technologies of the conversion systems, it is far from clear which of them is the optimal, regarding the impacts on capacity factors of wind farms.

The motivation for this work is supported by the absence of a deterministic certainty in allocating outputs of wind farms, concerning the technological conversion system trends [4, 5]. Therefore, this study intends to explore the impact of the technological conversion energy system on farms performance, based on Data Envelopment Analysis (DEA). The performance of wind farms can be measured by their productivity and efficiency. The productivity is defined by the ratio output/input for each farm (absolute concept) and can be affected by exogenous variables, such as the wind availability and variability. The efficiency compares the ratio output/input in each farm with the best ratio observed among all farms (relative concept). The DEA models enable to compute the Malmquist index to compare groups [6] by assessing the efficiency and productivity of wind farms. The robustness of the efficiencies scores derived from DEA models can be tested by using bootstrapping framework [7].

This study applies the described methodology to assess the performance of wind farms and groups comparison which use two main conversion system technologies: 
drive trains based on geared doubly fed induction generators and partial scaled electronic converter (Asynchronous group) and gearless synchronous generator with full power electronic converter (Synchronous group).

The paper is organized as follows: next section presents technological trends on wind energy conversion systems, Section III overviews the DEA method and the Malmquist index for groups performance comparison, Sections IV and V apply the proposed approach to a case study, present and discuss the main results and Section $\mathrm{V}$ rounds up the paper with the main conclusions.

\section{WIND ENERGY CONVERSION SYSTEM TECHNOLOGIES}

Despite the fact first development of commercial wind energy technology began in the late 1930s, only after the oil crises of the 1970s, there have begun economical incentives to develop the technology further [8]. Since the 1980s, there has been a significant consolidation of the design of wind turbines. This section describes main design styles in wind energy conversions systems and points out the technology trends.

\section{A. Design Styles}

The mainstream commercial market uses horizontal axis wind turbines, meaning the rotating axis is parallel to the ground. This option is inherently more efficient than vertical axis. Concerning the number of blades, the aerodynamic efficiency and reduced acoustic noise emission establish three-bladed rotor design.

Other important issue related with the design of a wind energy conversion system is the process of limiting rotor power in high operational wind speeds. There are two main approaches: stall and pitch control.

In stall regulated machines, speed regulation is intrinsic to the aerodynamic design, without any change of the rotor geometry. Under this control approach, wind turbine runs at approximately constant speed even when the wind speed is high, without producing excessive power. The constant speed is achieved through the connection of the electric generator to the grid. Regarding this aspect, the grid behaves like a large flywheel, holding the speed of the turbine nearly constant irrespective of changes in wind speed.

Pitch control involves pitching the blades (i.e., turning the wind blades about their main axis) in order to regulate the power the rotor extracts from wind. This control involves an active control system, which should sense the blade position and defines appropriate changes of blade pitch, according to the measured output power.

Another important and decisive design issue of the wind turbines is the use of variable rotational speed versus fixed speed, with consequences on the overall performance of the system $[9,10]$.

The constant speed turbine designs consist on generators operating at fixed speed when producing power, directly connected to the utility grid which, through the generator, holds the speed constant. This concept makes use of Squirrel Cage Induction Generators (SCIG) with a geared drive train to adapt the rotational speed to the frequency of the grid. The wind energy captured and also the power quality in the utility grid are reduced.

Variable speed wind energy systems in operation below rated power enable increased energy capture, and above rated power, even over quite a small speed range, can substantially ease pitch system duty and reduce output power variability, which in turn improve the power quality when compared with constant speed systems. This concept may be implemented using synchronous or asynchronous generators, allowing wider or narrower wind speed ranges, respectively.

Solutions based on asynchronous generators, the so called Doubly Fed Induction Generators (DFIG), with the stator windings directly connected to the grid and a partial scaled electronic converter between the rotor and the grid, allow a low to moderate variation of the rotor speed. Since the power converter is partially scaled, typically one third of the rated power of the system [11], this solution is somewhat cost effective but, on the other hand, there are limitations to control effectively the grid variables, which translates in a deficient quality power system [12]. It should be pointed out that this concept uses a geared drive train to match the low rotational speed promoted by wind velocities to the higher efficient rotational speed of this generator type.

Solutions based on Synchronous Generators (SG) use full scaled electronic converters. The electrical energy is generated at variable frequency (strictly related to the rotational speed of the rotor) and then converted to the frequency of the grid. This concept takes advantage of the wide speed range operation allowed by the full scale converter between the generator and the grid, which also allows boosting the grid stability and performance. Additionally, this type of generators requires lower ratio gearboxes (or even its omission) than DFIG, which translates in higher reliability and lower maintenance costs [12].

\section{B. Technological Trends}

Due to the high wind speed variability and intermittency, the actual demand on power quality issues claims for generators featuring variable speed, which is the dominant trend in the actual market.

Comparing partial speed range systems, promoted by DFIG, and full-range variable speed drives based on SG, the later bring some attractions, specially on operational flexibility and power quality issues, but also have some drawbacks related with the higher nameplate power of the electronic converter, with the same rating of the generator [13]. In fact, there was never a clear case for full variable speed range on economic grounds, with small energy gains being offset by extra costs and also additional losses in the power converter.

Another technological trend is related with direct driven generators, i.e., gearless systems. The direct drive systems of Enercon [14] are long established, and gearless systems, or systems with low ratio gearboxes using Permanent Magnet Synchronous Generators 
(PMSG) have emerged in recent years [15]. In fact, some manufacturers that in past had based their technology on asynchronous generators are now moving to PMSG with full scaled converter [16].

Permanent magnet technology allows a higher powerto-volume-ratio of the drive train, and fully rated power converter based systems can be applied without design hardware modifications in both $50 \mathrm{~Hz}$ or $60 \mathrm{~Hz}$ power systems, which increases flexibility for international developers operating in multiple wind markets [8].

Concerning the power control in high operational wind speeds, the design issues of pitch versus stall and the degree of rotor speed variation are evidently connected. The stall-regulated design remains viable, but pitch control offers potentially better output power quality, while overall costs of both systems remain similar [8].

\section{Performance Assessment Methodology}

The original DEA model [17] is used to assess the farms efficiency in producing electric energy from the physical resources and the wind available in each farm. The efficiency scores can be used to calculate the Malmquist-type index for groups comparison [6, 18], which enables to compare the overall performance of wind farms using the two conversion system technologies under analysis. Malmquist index can be decomposed in two components: the $I E$ for comparing the differences between groups in terms of the efficiency spread in each group of farms and the $I F$ for comparing the productivity differences between the "best-practices" frontiers defined by the benchmark farms from each group. In order to correct the efficiency estimates for the bias, the bootstrapping approach [7] is applied, which is the suitable framework for the DEA method.

\section{A. DEA Model}

DEA is a non-parametric method to assess the relative efficiency of a homogeneous set of Decision Making Units (DMU) which use multiple inputs to produce multiple outputs. In the DEA model, the efficiency score of each DMU is estimated by using the frontier technology defined by the identification of the observed "best practices" DMU and their linear combination.

In order to describe the formulation of the DEA model, for an output maximizing perspective and constant returns to scale, the production possibility set (PPS) is given by $n$ DMU $(j=1, \ldots, n)$ which use $m$ inputs $x_{i j}\left(x_{1 j}, \ldots, x_{m j}\right) \in \mathbb{R}_{+}^{m}$ to produce $t$ outputs $y_{r j}\left(y_{1 j}, \ldots, y_{t j}\right) \in \mathbb{R}_{+}^{m}$. The relative efficiency of each $\mathrm{DMU}_{o}$ can be assessed using the following linear programming model [17]:

$$
\begin{aligned}
& \operatorname{Max}\left\{h_{o} \mid x_{i 0} \geq \sum_{j=1}^{n} \lambda_{j} x_{i j}, i=1, \ldots, m,\right. \\
& \left.h_{o} y_{r o} \leq \sum_{j=1}^{n} \lambda_{j} y_{r j}, r=1, \ldots, t, \lambda_{j} \geq 0, \forall j\right\}
\end{aligned}
$$

The model (1) assesses the efficiency score, $\theta_{o}$, of the $\mathrm{DMU}_{o}$ under evaluation, which is to the inverse of the optimum solution of $h_{o}$. This value corresponds to the factor by which the outputs of the $\mathrm{DMU}_{o}$ can be expanded given the current level of resources used by the farm. The relative efficiency score, given by $\theta_{o}$, is equal to $100 \%$, if the farm is efficient whereas lower scores indicate the presence of inefficiencies in the production process. The efficient units are located in the frontier technology identified by the DEA model. For the inefficient units, there is evidence that it is possible to obtain higher levels of outputs with the same or lower levels of the inputs currently used. For each farm, in order to correct the efficiency estimates for the bias, the bootstrapping approach [7] is applied to calculate the confidence interval, the bias and the bias-corrected efficiency, $\hat{\theta}_{o}$. The bias-corrected efficiency scores are used to assess the wind farms performance and to compute the Malmquist index and its components.

\section{B. Malmquist Index for Groups Comparison}

The Malmquist index (MI) was introduced by Caves et al. [19], developed further in the context for measurement of productivity change over time by Färe et al.[20] and extended by Camanho and Dyson [18] for comparing different groups. This study uses the output oriented version of the MI, presented in [6], which is consistent with the objectives of the problem under analysis. MI computation is based on radial measures, defined by output distance functions, which are equal to the efficiency score estimated by the DEA model previously introduced, given by $\theta_{o}$, for each $\mathrm{DMU}_{o}$. The following overview reviews the output oriented version of the MI.

Considering $\delta_{A}$ farms in group $A$, which use the inputs $x^{A} \in \mathbb{R}_{+}^{m}$ to produce the outputs $y^{A} \in \mathbb{R}_{+}^{m}$, and $\delta_{S}$ farms in group $S$, which use the inputs $x^{S} \in \mathbb{R}_{+}^{m}$ to produce the outputs $y^{S} \in \mathbb{R}_{+}^{m}$, the MI aggregates the efficiency estimates obtained for all farms in each group through a geometric average, as follows:

$$
I^{A S}=\left[\frac{\left[\prod_{j=1}^{\delta_{A}} E^{A}\left(x_{j}^{A}, y_{j}^{A}\right)\right]^{\frac{1}{\delta_{A}}}}{\left[\prod_{j=1}^{\delta_{S}} E^{A}\left(x_{j}^{S}, y_{j}^{S}\right)\right]^{\frac{1}{\delta_{S}}}} \times \frac{\left[\prod_{j=1}^{\delta_{A}} E^{S}\left(x_{j}^{A}, y_{j}^{A}\right)\right]^{\frac{1}{\delta_{A}}}}{\left[\prod_{j=1}^{\delta_{S}} E^{S}\left(x_{j}^{S}, y_{j}^{S}\right)\right]^{\frac{1}{\delta_{S}}}}\right]^{\frac{1}{2}}
$$

where the efficiency estimates' superscript denotes the frontier technology group used as reference to calculate the efficiency for the assessed farm, $j$.

This aggregation enables to compare globally the 
groups' performance. A score of $I^{A S}>1$ indicates that group $A$ performs better than group $S$.

According to [20], this index can be decomposed in two components, i.e.,

$$
I^{A S}=I E^{A S} \times I F^{A S}
$$

where $I E^{A S}$ compares the efficiency spread within the groups and the other component $I F^{A S}$ compares the relative position of the group frontiers. This decomposition means that the sources of better performance can be associated with two factors: less dispersion in the efficiency scores of the DMU within the group, and/or better productivity associated to the group frontier.

The first component, $I E^{A S}$, is given by

$$
I E^{A S}=\frac{\left[\prod_{j=1}^{\delta_{A}} E^{A}\left(x_{j}^{A}, y_{j}^{A}\right)\right]^{\frac{1}{\delta_{A}}}}{\left[\prod_{j=1}^{\delta_{S}} E^{S}\left(x_{j}^{S}, y_{j}^{S}\right)\right]^{\frac{1}{\delta_{S}}}}
$$

where a value of $I E^{A S}>1$ means that the efficiency spread is smaller in farms from group $A$ than in farms from group $S$.

Regarding the second component, $I F^{A S}$, it is obtained as the geometric mean of two ratios: the first one is the geometric mean of the distances between the frontiers $A$ and $S$, when assessed for the farms in group $A$ and the second ratio is calculated in a similar way for the farms in group $S$, as follows:

$$
I F^{A S}=\left[\left(\prod_{j=1}^{\delta_{A}} \frac{E^{S}\left(x_{j}^{A}, y_{j}^{A}\right)}{E^{A}\left(x_{j}^{A}, y_{j}^{A}\right)}\right)^{\frac{1}{\delta_{A}}} \times\left(\prod_{j=1}^{\delta_{S}} \frac{E^{S}\left(x_{j}^{S}, y_{j}^{S}\right)}{E^{A}\left(x_{j}^{S}, y_{j}^{S}\right)}\right)^{\frac{1}{\delta_{S}}}\right]^{\frac{1}{2}}
$$

A value of $I F^{A S}>1$ indicates greater productivity of the frontier of group $A$ than the frontier of group $S$, on average. Thus, to complement the information given by this component, it is necessary to explore if the frontiers cross over for each DMU. This analysis is performed by exploring the ratios of eq. (5) which estimate the distance between the two group frontiers. For each farm $j$ in group $k$, if the ratio $E^{S}\left(x_{j}^{k}, y_{j}^{k}\right) / E^{A}\left(x_{j}^{k}, y_{j}^{k}\right)$ is higher than 1 means that the group $A$ frontier has higher productivity than the group $S$ frontier for the input-output mix in consideration. Therefore, a confidence interval can be computed for each farm, based on Simar and Wilson approach [21]. If the interval contains the value " 1 " it is not possible to infer that productivity of both group frontiers are different for the input-output mix observed in each farm. On the other hand, if the lower and upper bounds are smaller (or greater) than "1", this means that the productivity of the frontier $A$ is lower (higher) than the productivity of the frontier $S$ for the input-output mix observed in that farm. This analysis should be performed for all farms observed, which allows the exploitation of the group frontiers' position for the observed input-output mix.

\section{CAse Study}

The proposed methodology is applied to explore the differences in performance of a set of wind farms, which involves two conversion system technologies: the first group is based on Asynchronous generators and the second one uses drive trains based on Synchronous generators, hereafter denominated groups $A$ and $S$, respectively. The number of farms under analysis in each group is 15 , with an installed power ranging from 10 to $60 \mathrm{MW}$, from five different manufacturers. A panel data set regarding 2010 and 2011 years was collected from Annual Reports and Accounts from two major promoters acting on the wind energy sector in Portugal and the wind data was collected from a meteorological data base throughout identification of the station which best represents the wind farm profile, defined by the nearest meteorological station.

To remove any bias from the analysis, involving unequally sized samples comparison, the number of farms under analysis in each group is equal, i.e., the final data set considers 30 entries for each group, considering the two groups in both years. The output-oriented perspective is used, as the objective is to assess the ability of each wind farm to maximize the electric energy produced, taking into account the wind, and the resources available in each farm, during the period under analysis.

In order to model the farm activity in the DEA model, the input-output set should cover the full range of resources used and the outputs that are relevant for the objectives of the analysis. The resources included in the DEA model are the installed capacity (MW), rotor diameter $(\mathrm{m})$, number of wind turbines, number of available hours between cut-in and cut-out wind speeds (named "wind hours") and the average wind speed $(\mathrm{m} / \mathrm{s})$. Concerning the output, it corresponds to the net production (GWh). Table I summarizes the descriptive statistics concerning the variables under analysis for the observed units included in each group, for each year.

\begin{tabular}{|c|c|c|c|c|c|}
\hline & & \multicolumn{2}{|c|}{ Year 2010} & \multicolumn{2}{|c|}{ Year 2011} \\
\hline & & Mean & Sta.Dev. & Mean & Sta.Dev. \\
\hline \multirow{6}{*}{$\begin{array}{l}n \\
\vdots \\
\vdots \\
\vdots \\
b\end{array}$} & Installed capacity (MW) & 22,7 & 8,9 & 23,0 & 9,0 \\
\hline & Rotor diameter (m) & 75,5 & 9,6 & 75,5 & 9,6 \\
\hline & Wind turbines & 13,1 & 5,5 & 13,1 & 5,5 \\
\hline & Wind hours & 3592,0 & 1974,4 & 3130,4 & 2018,7 \\
\hline & Wind speed $(\mathrm{m} / \mathrm{s})$ & 4,8 & 1,9 & 4,2 & 1,7 \\
\hline & Net production (GWh) & 55,8 & 20,7 & 53,3 & 21,7 \\
\hline \multirow{6}{*}{ 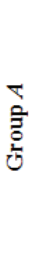 } & Installed capacity (MW) & 20,2 & 15,0 & 20,2 & 15,0 \\
\hline & Rotor diameter (m) & 84,9 & 5,0 & 84,9 & 5,0 \\
\hline & Wind turbines & 9,2 & 5,7 & 9,2 & 5,7 \\
\hline & Wind hours & 3710,1 & 1857,4 & 3596,7 & 1453,9 \\
\hline & Wind speed $(\mathrm{m} / \mathrm{s})$ & 4,8 & 1,7 & 4,7 & 1,2 \\
\hline & Net production (GWh) & 52,1 & 43,1 & 46,8 & 38,9 \\
\hline
\end{tabular}

TABLE I

DESCRIPTIVE STATISTICS OF THE DATA UNDER ANALYSIS 


\section{RESUlTS AND DisCUSSION}

Performance assessment of wind farms efficiency and comparison of wind energy conversion system technologies groups using Malmquist Index are presented below.

\section{A. Performance Assessment of Wind Farms Efficiency}

Concerning the performance assessment of wind farms, the efficiency score for each farm in each year is estimated based on comparison with a pooled frontier corresponding to the "best practices" observed in the two years under analysis. Table II reports the summarized results for the bias-corrected efficiency scores, the estimated efficiency scores, the bias and the number of efficient farms, in each year analysed and group.

TABLE II

SUMMARY RESULTS OF ORIGINAL AND BOOTSTRAPPED EFFICIENCY ESTIMATES

\begin{tabular}{|c|c|c|c|c|c|}
\hline & & $\begin{array}{l}\text { Efficiency } \\
\text { estimated }\end{array}$ & $\begin{array}{l}\text { Bias correct. } \\
\text { efficiency }\end{array}$ & Bias & $\begin{array}{l}\mathrm{N} .^{\circ} \text { efficient } \\
\text { farms }\end{array}$ \\
\hline \multirow{3}{*}{ 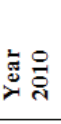 } & All farms & $87,85 \%$ & $85,22 \%$ & $3,54 \%$ & 4 \\
\hline & Group $A$ & $87,46 \%$ & $84,60 \%$ & $3,73 \%$ & 3 \\
\hline & Group $S$ & $88,24 \%$ & $85,83 \%$ & $3,34 \%$ & 1 \\
\hline \multirow{3}{*}{ 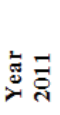 } & All farms & $81,51 \%$ & $78,77 \%$ & $4,03 \%$ & 2 \\
\hline & Group $A$ & $79,39 \%$ & $77,05 \%$ & $3,59 \%$ & 0 \\
\hline & Group $S$ & $83,64 \%$ & $80,50 \%$ & $4,46 \%$ & 2 \\
\hline
\end{tabular}

Globally, wind farms analysed are more efficient in 2010 than in 2011. This efficiency deterioration may be partially explained by the meteorological data which shows that there had been a declining in wind potential from 2010 to 2011. In both years, the wind farms using synchronous generators (group $S$ ) are slightly more efficient than the ones based on asynchronous generators (group A), on average, although the "best practices" frontier observed in the two years analysed is defined by 3 farms from group $A$ and by 3 farms from group $S$.

\section{B. Comparison of Conversion System Technologies Groups}

Comparison of efficiency spread between group $A$ and group $S$, evaluated by $I E^{A S}$ index is 0,945 ( $c f$. Fig. 1), indicating that farms from group $S$ are closer to their "best practices" frontier (average efficiency within group $S$ is equal to 0,836 ) than the farms from group $A$ (average efficiency within this group is equal to 0,793). Thus, there is potential for improving the efficiency within both groups, in particular for the farms in group $A$.

Regarding the relative position of the frontiers, the frontier productivity index, $I F^{A S}$, is equal to 1,044 ( $c f$. Fig. 1), which means that the productivity frontier of the farms using asynchronous generators (group $A$ ) is slightly greater than productivity frontier of the farms using synchronous generators (group $S$ ), on average. Since this indicator is computed from distances between both frontiers, it is necessary to explore their relative position by computing a confidence interval for each farm [10].
The significant ratios are summarized in Table III.

TABLE III

Significant SCORES OF the Ratios that Estimate THE Distance BetWEen Frontiers for EACH Group $\left[E^{S}\left(x_{j}^{k}, y_{j}^{k}\right) / E^{A}\left(x_{j}^{k}, y_{j}^{k}\right)\right]$

\begin{tabular}{ccc}
\hline & $\begin{array}{c}\mathbf{N}^{\circ} \text { of farms } \\
\text { with ratio }>1\end{array}$ & $\begin{array}{c}\mathbf{N}^{\circ} \text { of farms } \\
\text { with ratio }<1\end{array}$ \\
\hline $\begin{array}{c}\text { Farms using Asynchronous } \\
\text { generators }(k=A)\end{array}$ & 12 & - \\
\hline $\begin{array}{c}\text { Farms using Synchronous } \\
\text { generators }(k=S)\end{array}$ & 3 & 2 \\
\hline
\end{tabular}

From these results, there are 12 farms in group $A$ and 3 farms in group $S$ which are located in the area of the PPS where the frontier of group $A$ is more productive. The opposite situation occurs for 2 farms in group $S$ located in area of the PPS where the frontier of group $S$ is more productive. This situation indicates that frontiers crossed over and, for some input-output mix, the productivity frontier of the farms using synchronous generators is also greater than the productivity frontier of the farms using asynchronous generators. Globally, the frontiers crossed over for some input-output mix and also for other inputoutput mix there are no productivity differences between the two groups analysed. From these results, it is possible to conclude that the "best practices" can be observed in farms from both groups, which implies that the decision maker can assess the farms efficiency based on comparison with a pooled frontier defined by the "best practices" observed in the farms using asynchronous and synchronous generators. The pooled "best practices" frontiers has been used in DEA assessment described in the previous subsection.

Fig. 1 summaries the values of the overall Malmquist index and its components. The index reflecting the overall group performance, $I^{A S}$, is equal to 0,986 , which aggregates the global comparison of the two groups.

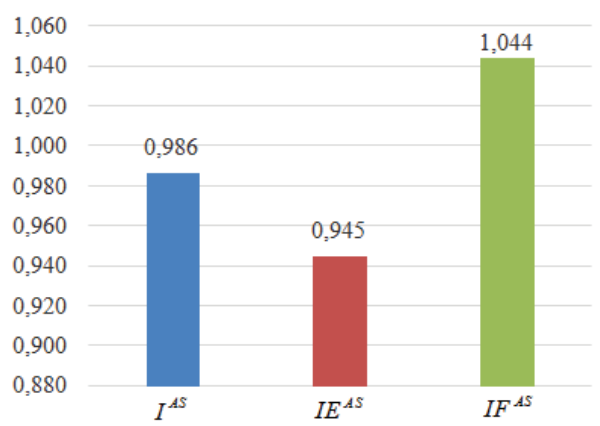

Fig. 1. Malmquist index and its components.

From the obtained results, it is possible to infer that farms using asynchronous generators perform lower than farms using synchronous generators due to the higher spread efficiency, although a slight higher productivity of their "best practices" frontier is observed for some extent of the input-output mix. The best performance of farms based on synchronous generators is derived from the smallest dispersion of the farms regarding the "best practices" frontier observed. Furthermore, for some 
input-output mix, the productivity of their "best practices" frontier is slightly higher than the one of the farms based on asynchronous generators.

\section{CONCLUSION}

The proposed methodology based on DEA enables to understand how the conversion system technologies impact on the efficiency and productivity of wind farms. The obtained results may support the decision makers in repowering and overpowering processes.

From pooled analysis, it can be concluded that farms using technology based on gearless synchronous generators (group $S$ ) perform slightly better than farms using geared doubly fed induction generators (group $A$ ).

The use of the MI enables to compare globally the performance of the wind energy conversion systems technology groups. The decomposition of this index in its components allows to compare the efficiency spread in each group and the productivity differences between the "best-practices" frontiers of each group. This analysis indicates that the farms from group $S$ are closer to their "best-practices" frontier than farms from group $A$. The exploitation of the productivity differences between the groups, highlights that there are "best practices" farms in both groups for some input-output mix while for the other input-output mix there are no productivity differences between the groups considered.

Therefore, the best performance of synchronous generators is derived from the smallest dispersion of the farms regarding the "best practices" frontier observed. This conclusion is consistent with the wider wind speed range allowed by drive trains based in these generators, even when the exogenous input, the wind, is lower, as in the case study under analysis.

\section{REFERENCES}

[1] ENEOP. (2014, January, 2014). Eólicas de Portugal, S.A. Available: http://www.eneop.pt/

[2] M. Denault, et al., "Complementarity of Hydro and Wind Power: Improving the Risk Profile of Energy Inflows", Energy Policy, vol. 37, (12) pp. 5376-5384, 2009.

[3] R. Karki and R. Billinton, "Cost-Effective Wind Energy Utilization for Reliable Power Supply", IEEE Transactions on Energy Conversion, vol. 19, (2) pp. 435-440, 2004.

[4] H. Arabian-Hoseynabadi, et al., "Reliability Comparison of Direct Drive and Geared Drive Wind Turbine Concepts", Wind Energy, Wiley Online Library, vol. 13, (1) pp. 62-73, 2010.

[5] H. Polinder, et al., "Comparison of Direct-Drive and Geared Generator Concepts for Wind Turbines", IEEE
Transactions on Energy Conversion, vol. 21, (3) pp. 725733, September 2006.

[6] C. B. Vaz and A. S. Camanho, "Performance comparison of retailing stores using a Malmquist-type index", Journal of the Operational Research Society, vol. 63, pp. 631-645, 2012.

[7] L. Simar and P. W. Wilson, "Sensitivity Analysis of Efficiency Scores: How to Bootstrap in Nonparametric Frontier Models", Management Science, vol. 44, (1) pp. 49-61, 1998.

[8] EWEA, Wind Energy - The Facts: Routledge, 2009.

[9] A. D. Hansen, et al., "Review of Contemporary Wind Turbine Concepts and their Market Penetration", Wind Engineering, vol. 28, (3) pp. 247-263, 2004.

[10] P. Mutschler and R. Hoffmann, "Comparison of Wind Turbines Regarding their Energy Generation", in IEEE 33rd Annual Power Electronics Specialists Conference, PESC, 2002, pp. 6-11.

[11] F. Blaabjerg, et al., "Trends in Power Electronics and Control of Renewable Energy Systems", in 14th International Power Electronics and Motion Control Conference (EPE-PEMC 2010), Ohrid, Republic of Macedonia, 2010, pp. k1-k19.

[12] S. Mathew and G. S. Philip, Advances in Wind Energy and Conversion Technology: Springer, 2011.

[13] J. A. Baroudi, et al., "A Review of Power Converter Topologies for Wind Generators", Renewable Energy, Elsevier, vol. 32, (14) pp. 2369-2385, 2007.

[14] Enercon. (2011, June, 2011). Enercon - Technology. Available: http://www.enercon.de/en-en/21.htm

[15] J. F. Conroy and R. Watson, "Low-Voltage Ride-Through of a Full Converter Wind Turbine with Permanent Magnet Generator", Renewable Power Generation, IET, vol. 1, (3) pp. 182-189, 2007.

[16] GE_Energy. (2011, June, 2011). Wind Turbines. Available: http://www.ge-energy.com/products_and_services/ products/wind turbines/

[17] A. Charnes, et al., "Measuring the efficiency of decision making units", European Journal of Operational Research, vol. 2, (6) pp. 429-444, 1978.

[18] A. S. Camanho and R. G. Dyson, "Data envelopment analysis and Malmquist indices for measuring group performance", Journal of Productivity Analysis, vol. 26, (1) pp. 35-49, 2006.

[19] D. W. Caves, et al., "The Economic Theory of Index Numbers and the Measurement of Input, Output, and Productivity", Econometrica, vol. 50, pp. 1393-1414, November 11982.

[20] R. Färe, et al., "Productivity Growth, Technical Progress, and Efficiency Change in Industrialized Countries", The American Economic Review, vol. 84, pp. 66-83, March 1 1994.

[21] L. Simar and P. W. Wilson, "Estimating and bootstrapping Malmquist indices", European Journal of Operational Research, vol. 115, (3) pp. 459-471, 1999. 